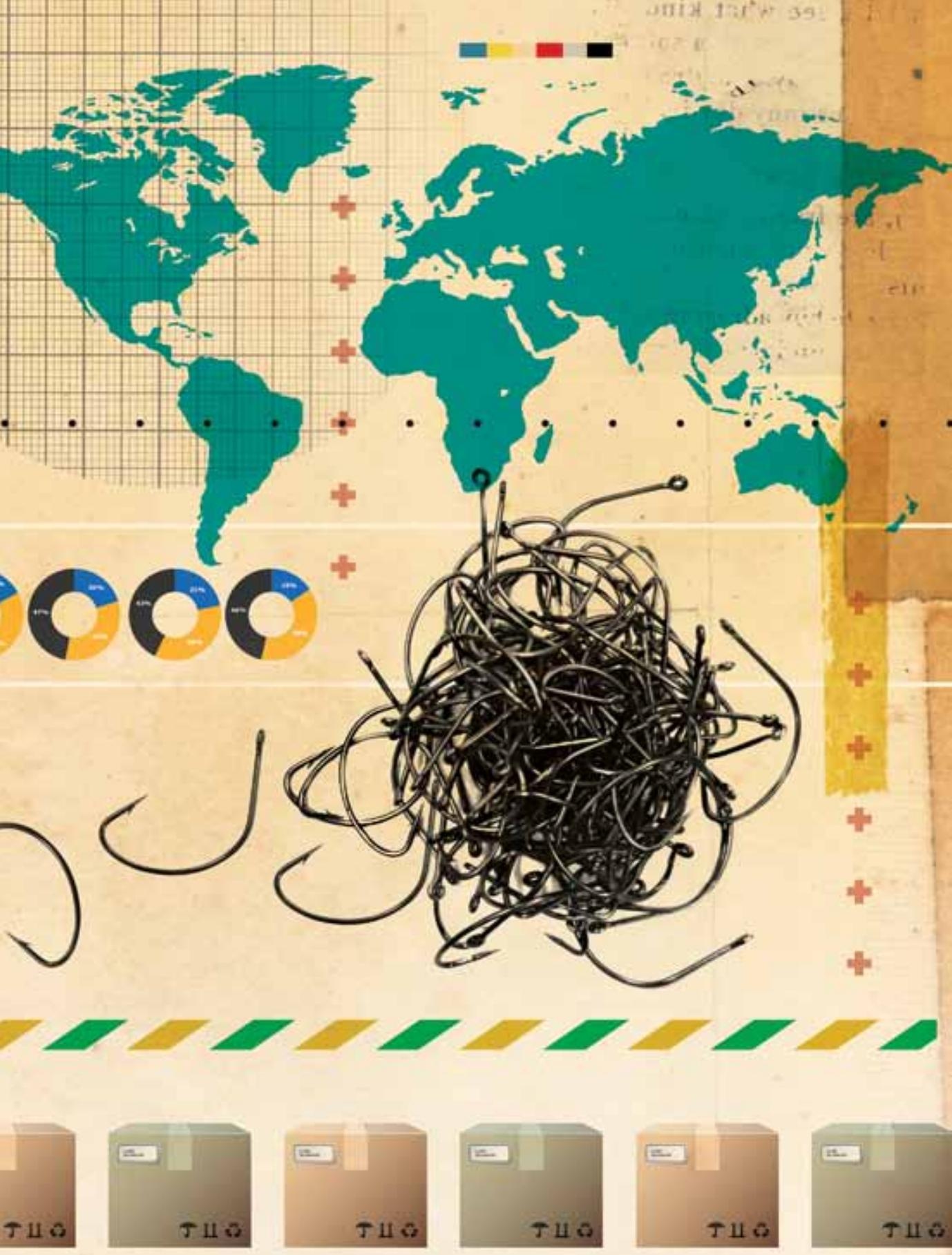




\title{
Especialização primória como limite ao desenvolvimento
}

\author{
Primary specialization as limit to \\ development
}

Guilherme Costa Delgado

\section{Resumo}

Este artigo analisa a especialização primária do comércio exterior brasileiro nos anos 2000, articulada como política, em resposta ao desequilíbrio estrutural das transações externas, especialmente dos 'Serviços' e da 'Indústria de Transformação'. Conquanto conjunturalmente compensatória, a especialização primária das exportações não resolve a dependência externa e agrava a situação deficitária dos demais setores.

Esse modelo de inserção externa, fortemente apoiado em produtividade de recursos naturais (no comércio externo) e captura de renda fundiária (pelos proprietários de recursos naturais), contem sérios limites ao desenvolvimento. Produção e repartição do excedente econômico, em tais condições, provocam armadilhas produtivas (super exploração de recursos naturais) e distributivas (concentração da riqueza fundiária), de sorte a constranger o crescimento econômico à reprodução de padrões de sub-desenvolvimento.

Palavras-Chaves: Desenvolvimento,agricultura, relações econômicas externas e questão agrária

\begin{abstract}
This paper analyze the Brazilian specialization on commodity exports in recent years (decade -2000), as answer to external disequilibrium. Strong deficits on 'Services' and low competitiveness on manufactures have been compensated, by commodity exports. In spite of short time compensation, the original disequilibrium isn't solved but increase like a structural dependence.

This model of insertion on global trade is supported by two economical arrangements: comparative advantages on natural resource intended by trade agents and capture of land rents by landowners. In this context, there are tramps for development on production and distribution of the economic surplus. In the first case, the external dependence on commodities imposes a bias for over exploitation of natural resource. In the second case, there is a trend for concentration on a land rent approach of agricultural expansion. These conditions - on commerce, production and distribution, configure criteria for reproduction of the sub-development.
\end{abstract}

Key words: Development/agriculture/international economic relationship and agrarioan question 


\section{Introdução}

Este artigo se propõe explicar integradamente três movimentos de um processo

Edeterminado, que assume protagonismo na economia brasileira dos anos 2000, a ponto de praticamente configurar em uma década o perfil dominante no comércio exterior, com repercussões para o sistema econômico.

O primeiro movimento desse mencionado arranjo da economia brasileira na década 2000 é sua forte expansão em termos de comércio exterior, pautada pelo crescimento das exportações primárias e perda relativa das exportações manufatureiras. Aparentemente tal desempenho corresponderia a uma nova inserção do Brasil na divisão internacional do trabalho, de maneira a responder a situação de dependência por recursos externos que desencadeara a grave crise cambial de 1999. Mas a dependência reaparecerá transformada, como se verá na análise do texto.

O segundo movimento éa reestruturação de um virtual pacto de economia política depois da crise cambial de 1999, de sorte a articular a acumulação de capital no setor rural como política de Estado: a expansão das cadeias agroindustriais, do sistema de crédito público e do mercado de terras, coetânea à expansão dos mercados mundiais de 'commodities'. Tal estratégia, típica de 'capital financeiro na agricultura', merecerá esclarecimento conceitual, porque em geral é apresentada sob a denominação de expansão do agronegócio, expressão empiricamente útil, mas teoricamente não significativa aos propósitos analítico ora perseguidos.

O terceiro componente relevante, que configura certo amálgama aos dois anteriores, é a forma como o sistema econômico produz e extrai excedente econômico pelo setor primário. $O$ conceito a se recuperar nesse contexto é o da renda fundiária, no seu sentido clássico de lucro extraordinário que a propriedade de terras, jazidas minerais, águas e campos petroleiros confere aos detentores desses recursos naturais. Obviamente não estamos descartando progresso técnico na produção e extração do excedente econômico por essa via, mas revelando seus condicionamentos e limites econômicos, sociais e ambientais.

Finalmente vamos discutir criticamente as consequências desses movimentos estratégicos de um arranjo peculiar de economia política, sob a perspectiva teórica do desenvolvimento na visão de Celso Furtado (2010).

Observe-se que a nova inserção da economia brasileira delineada no primeiro movimento, impele a reorganização da economia do agronegócio (segundo movimento) relativamente divorciada da indústria. Por sua vez, a perseguição das vantagens comparativas naturais e da renda fundiária, faces dobradas de uma mesma moeda, assumem a condição de móvel principal da acumulação. Esse processo gera acumulação de capital, tendo por fator causal a demanda externa pelo setor primário. Distinto é o processo que se desencadearia pelo circuito causal do progresso técnico, abrindo fronteiras à acumulação de capital e nesse processo criando demanda interna e externa ou atendendo demandas pré-existentes. 


\section{Condiçōes Internas e Externas para o Relançamento da Economia do Agronegócio Depois da Crise Cambial de 1999}

Em final de 1998 uma crise de liquidez internacional afeta a economia brasileira, provocando enorme fuga de capital e forçando a mudança do regime cambial. Desde então a política do ajuste externo se altera. Recorre-se forçosamente aos empréstimos do Fundo Monetário Internacional (FMI) em três sucessivas operações de socorro $-1999,2001$ e 2003.

A política de comércio exterior é alterada ao longo do segundo governo $\mathrm{FHC}$ e passa a perseguir a estratégia que abandonara em 1994: gerar saldos de comércio exterior a qualquer custo, tendo em vista suprir o déficit da Conta Corrente. Este, por seu turno, se exacerba, pela pressão das saídas de rendas de capital, antes mesmo que se fizessem sentir os efeitos da reversão na política de comércio externo (ver a comparação do déficit na Conta Corrente com os saldos comerciais entre 2000 e 2010 na tabela 1)

Acrescente-se ainda, que ocorre fuga e não ingresso líquido de capitais no período imediatamente anterior e posterior à crise cambial (1996 até 2000). A Balança de Pagamentos ${ }^{1}$ apresenta déficit continuado, de sorte a promover acentuada perda de Reservas em moeda estrangeira

Outra vez, como ocorrera na primeira crise da dívida em 1982, os setores primárioexportadores são escalados para gerar esse saldo comercial. Nesse contexto, a agricultura capitalista, autodenominada de agronegócio, volta às prioridades da agenda da política macroeconômica externa e da política agrícola interna. Isto ocorre sob condições de desmontagem dos instrumentos de fomento agrícola no período precedente (anos 90), incluindo crédito rural, os preços de garantia, o investimento em pesquisa, e o investimento em infra-estrutura comercial - a exemplo dos serviços agropecuários, dos portos, da malha viária etc. Isto tudo, aliado à relativa desvantagem do País no comércio internacional durante o período do Real sobrevalorizado, adiou o relançamento da economia do agronegócio para o início do século XXI.

Observe-se que agronegócio na acepção brasileira do termo é uma associação do grande capital agroindustrial com a grande propriedade fundiária ${ }^{2}$. Essa associação realiza uma estratégia econômica de capital financeiro, perseguindo o lucro e a renda da terra, sob patrocínio de políticas de Estado.

O segundo governo do presidente Fernando Henrique Cardoso, 1998-2002, iniciou o relançamento do agronegócio, senão como política estruturada, com algumas iniciativas que ao final convergiram: (i) um programa prioritário de investimento em infra estrutura territorial, com "eixos de desenvolvimento", economias externas que incorporassem novos territórios, meios de transporte e corredores comerciais ao agronegócio: (ii) um explícito direcionamento do sistema público de pesquisa agropecuária (Embrapa), a operar em perfeita sincronia com empresas multinacionais do agronegócio; (iii) uma regulação frouxa do mercado de 
terras, de sorte a deixar fora do controle público as "terras devolutas", mais aquelas que declaradamente não cumprem a função social, além de boa parte das auto declaradas produtivas (ver análise da seção 5.4); (iv) mudança na política cambial, que ao eliminar naquela conjuntura a sobrevalorização do real, tornaria a economia do agronegócio competitiva junto ao comércio internacional e funcional para a estratégia do ajustamento macroeconômico perseguida; $(v)$ reativa-se a provisão do crédito rural nos Planos de Safra, iniciada com o programa MODERFROTA, e retomado a com vigor no período 2003/2010.

Este esforço de relançamento, forçado pelas circunstâncias cambiais de 1999, encontrará um comércio mundial muito receptivo na década 2000 para meia dúzia de commodities em rápida expansão ${ }^{4}$ nos ramos de 'feedgrains' (soja e milho), açúcarálcool, carnes (bovina e de aves) e celulose de madeira, que juntamente com os produtos minerais crescerão fortemente e passarão a dominar a pauta das exportações brasileiras no período 2000-2010, como mostra o gráfico 1.

Por outro lado, é preciso contextualizar o escopo macroeconômico sob o qual se deu o relançamento da estratégia do agronegócio no $2^{\circ}$ governo $\mathrm{FHC}$. Sua seqüência histórica é continuada e reforçada no $1^{\circ}$ governo Lula, com resultados macroeconômicos aparentemente imbatíveis. Mas já no $2^{\circ}$ governo Lula ocorrerá recrudescimento do desequilíbrio externo. Este desequilíbrio fora o motivo original da forçada opção por exportações primárias como espécie de solução conjuntural/ estrutural para o comércio exterior, que aparentemente livraria o País do déficit em Conta Corrente.

O sucesso aparente da solução exportadora significará na primeira década do século XXI uma quadruplicação do seu valor em dólares - o valor médio anual das exportações de 50,0 bilhões de dólares no período 1995/99 cresce para cerca de 200,0 bilhões no final da década de 2000; mas o grande campeão dessa evolução é a categoria dos produtos básicos, que pula de $25 \%$ da pauta para $45 \%$ em 2010 . Se somarmos aos produtos básicos os "semimanufaturados", que na verdade correspondem a uma pauta exportadora das cadeias agroindustriais e minerais, veremos que esse conjunto de exportações primárias - "básicos" + "semi-elaboradas" evoluirá de $44 \%$ no período $1995 / 99$ para $54,3 \%$ no triênio $2008 / 2010$, enquanto que de forma recíproca as exportações de manufaturados involuirão em termos proporcionais no mesmo período, caindo de $56 \%$ para $43,4 \%$ da pauta. Uma visualização gráfica para período mais longo - 1964-2010 a seguir mostra com clareza que o fenômeno da "reprimarização" do comércio exterior é efetivamente desta década dos anos 2000, em contraponto à fase áurea de crescimento da economia no período militar -1964-1984, quando há avanço proporcional da exportação dos manufaturados.

Mas o sucesso mais imediato da opção primário- exportadora caberá ao governo Lula no período 2003/2007, quando vigorosos saldos comerciais, oriundos dessas exportações, superaram o déficit de serviços da "Conta-Corrente", tornado-a superavitária, ${ }^{5}$. A partir de 2008, contudo, recrudescerá o déficit na Conta-Corrente, 
tornando frágil o argumento da via primária como solução estrutural para o desequilíbrio externo.

\section{Tabela 1}

Evolução e Composição das Transações Externas Correntes na Década de 2000 - (Bilhões de dólares)

\begin{tabular}{|l|l|l|l|}
\hline Períodos & $\begin{array}{l}\text { Saldo Médio da } \\
\text { Balança comercial }\end{array}$ & $\begin{array}{l}\text { Saldo médio da } \\
\text { Conta Serviços }\end{array}$ & $\begin{array}{l}\text { Total - Saldo da } \\
\text { Conta-Corrente }\end{array}$ \\
\hline $1995 / 99$ & $(-) 4,75$ & $(-) 23,71$ & $(-) 26,22$ \\
\hline $2000 / 2002$ & $+5,01$ & $(-) 25,26$ & $(-) 18,36$ \\
\hline $2003 / 2005$ & $+34,07$ & $(-) 27,86$ & $+9,92$ \\
\hline $2006 / 2007$ & $+43,06$ & $(-) 39,83$ & $+7,59$ \\
\hline 2008 & $+27,78$ & $(-) 57,23$ & $(-) 28,19$ \\
\hline 2009 & $+25,30$ & $(-) 52,90$ & $(-) 24,30$ \\
\hline 2010 & $+20,28$ & $(-) 70,63$ & $(-) 47,52$ \\
\hline
\end{tabular}

Obs.: O saldo da "Conta de Transações Correntes" é a soma algébrica dos saldos das Balanças - Comercial, de Serviços e das Transferências Unilaterais.

Gráfico 1

Exportação Brasileira por Fator Agregado 1964 a 2010 - Participação percentual sobre total

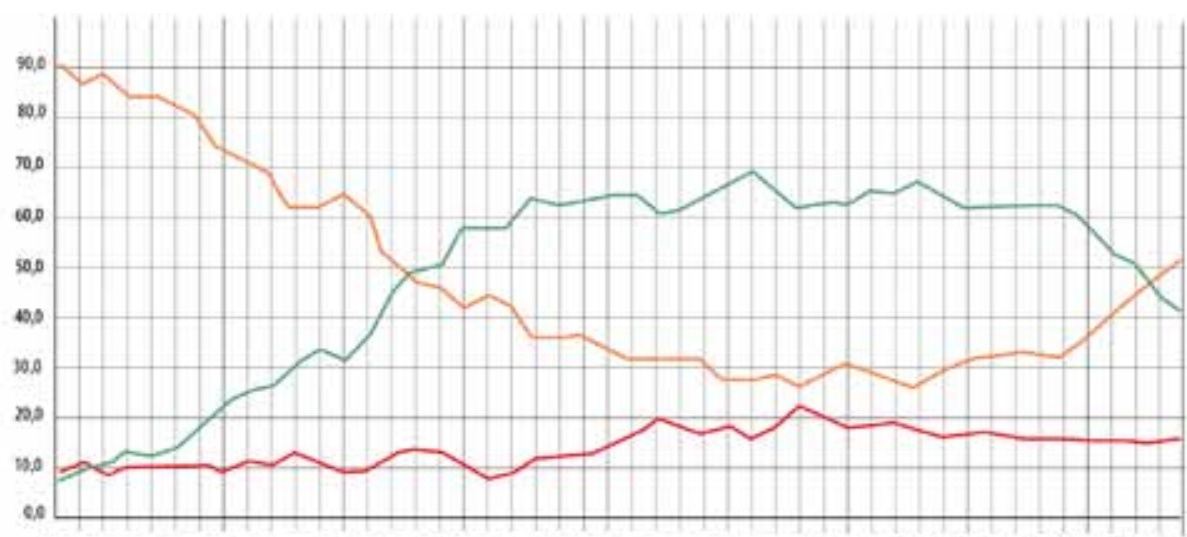

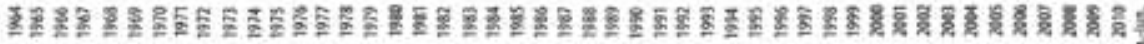

- Basicos

- Semimanufaturados

- Masdaturados

"Na verdade o que as "Transações Correntes" revelam, acrescido da informação da forte elevação das exportações 'Básicas"; e da forte perda relativa dos "Manufaturados", é indicação aparente de certa tendência à especialização no comércio exterior, de certa 
forma vinculada a compensar o déficit estrutural dos "Serviços". Estes serviços, por sua vez, refletem a remuneração do capital estrangeiro aqui aportado, sob diversos títulos, cuja resultante em termos de exportações líquidas é fortemente negativo. O setor primário é escalado para suprir esta brecha, e o faz de maneira exitosa nas conjunturas de crise cambial. Mas não é razoável imaginar esta equação conjuntural como solução estrutural ao desequilíbrio externo.

Dois fenômenos irão minar no tempo a estratégia primário-exportadora como solução ao desequilíbrio externo: 1) a perda de competitividade das exportações de manufaturadas, de maneira geral; 2) o crescimento exacerbado do déficit da Conta Serviços, atribuível ao maior peso do capital estrangeiro na economia brasileira, sem contrapartidas de exportações líquidas. A resultante desses fenômenos, agravada por outros fatores conjunturais, é o recrudescimento do déficit em Conta Corrente, a partir de 2008, com tendências à ampliação subseqüente.

Finalmente, deve-se atentar para o fato de que há na presente conjuntura certa confusão de situações críticas da economia mundial, que dificultam compreender a natureza vulnerável de nossa inserção externa. A via primária das exportações não resolve o desequilíbrio externo, mas é conjunturalmente uma fonte precária à solvência do Balanço de Pagamentos. Mas é absolutamente inviável como solução estrutural ao desequilíbrio externo, até mesmo porque a persistência do "déficit" no quadriênio 2008-2011 evidencia um custo de remuneração ao capital estrangeiro que não pode ser compensado por saldos comerciais, gerados pelas 'vantagens comparativas' das exportações primárias.

\section{Reestruturação da Economia do Agronegócio nos Anos 2000}

A expansão do mercado mundial de 'commodities' já era evidente no início dos anos 2000, impelida pelo acelerado crescimento da economia chinesa, grande responsável pelo notável crescimento do comércio exterior no período. Essa expansão terá influência marcante na economia brasileira, naqueles aspectos das relações internacionais, que analisamos no item precedente.

Mas haverá outra forte conexão com a economia agrícola brasileira, derivada desse 'boom de commodities'- a completa reversão do ciclo descensional do preço da terra, verificado no anos 90; para inaugurar um ciclo de elevação de preços na década dos anos 2000 até o presente. Para tal contribuiu o já mencionado movimento externo das 'commodities', mas também um outro conjunto de políticas internas, brevemente mencionadas no item anterior, que irão propiciar no Brasil o relançamento de uma peculiar estratégia de expansão agropecuária, autodenominada 'agronegócio".

Observe-se que em conexão ao ajuste macroeconômico que a política econômica realiza depois da grave crise cambial de 1999, de explícito sentido à reversão no déficit em Conta Corrente, reestrutura-se em paralelo um virtual pacto de economia política, relançado no presente, mas com características muito parecidas às de uma estratégia de 
capital financeiro agricultura, construída no período militar (1965-85) e desarticulada na fase mais ostensiva de liberalização dos mercados agrícolas (anos 90). O que fica evidente nos anos 2000 é o relançamento de alguns complexos agroindustriais, da grande propriedade fundiária e de determinadas políticas de Estado, tornando viável um peculiar projeto de acumulação de capital, para o qual é essencial a captura da renda de terra, juntamente com a lucratividade do conjunto dos capitais consorciadas no agronegócio.

As evidências empíricas apresentados neste item, Tabelas 2 e 3, e no item anterior, revelam em paralelo ao "boom" exportador de "commodities", processos de inflexão nos mercados e na política agrária, de caráter marcadamente internos: 1) reconstituise o crédito público bancário, sob a égide do Sistema Nacional de Crédito Rural como principal via de fomento da política agrícola, associada aos mecanismos de apoio e garantia da comercialização agropecuária (PGPM); 2) Os preços da terra e dos arrendamentos rurais experimentem uma substancial inflexão para cima em todas as regiões e para todos os tipos de terra, refletindo a alta das 'commodities'. Mas esses preços também são afetados pela forte liquidez bancária, associada às subvenções da política agrícola e de determinada frouxidão da política fundiária relativamente à regulação do mercado de terras; 3 ) aprofunda-se a inserção externa das cadeias agro industriais que manipulam com maior evidência as vantagens comparativas naturais da matéria prima principal do seu processo produtivo.

O crédito rural bancário que fora a principal via de favorecimento à agricultura no período militar, começara a declinar a partir de 1982, atingindo seu nível mais baixo no triênio 1995/97, quando o seu valor real concedido corresponde em índice a 18,7\%

Tabela 2

Expansão do crédito rural e de despesas conexas

\begin{tabular}{|l|l|l|}
\hline \multicolumn{1}{|c|}{ Variáveis } & $\begin{array}{l}\text { Índice de Valor Real do } \\
\text { Crédito Concedido pelo } \\
\text { SNCR }\end{array}$ & $\begin{array}{l}\text { Despesa Pública com } \\
\text { Subvenções -Crédito e PGPM } \\
\text { (Bilhões de Reais de 2010- } \\
\text { Média Anual) }\end{array}$ \\
\hline $1990 / 1992$ & 100,00 & - \\
\hline $2000 / 2002$ & 108,12 & 9,27 \\
\hline $2003 / 2005$ & 152,85 & 7,35 \\
\hline $2006 / 2008$ & 186,29 & 7,31 \\
\hline 2009 & 235,66 & 7,77 \\
\hline 2010 & 244,15 & 7,08 \\
\hline
\end{tabular}

Fontes - Col. 1 - Anuário Estatístico do Crédito Rural - BACEN - 2009 e 2010 (elaboração do autor). Col. 2 -Cf - Gasques, J. Garcia e Bastos, E. - citado in Delgado (2012) - Tabela 5.4 - op. cit 
TABELA 3

Variações Reais Médias do Preço da Terra em Fases Distintas do Ciclo Agropecuário: 1994-1997 e 2000/2006 (Terras de Lavoura)

\begin{tabular}{|l|l|l|}
\hline \multicolumn{1}{|c|}{ Períodos } & \multicolumn{1}{|c|}{ R994-1997 } & 2000/2006 \\
\hline Norte & Média Anual & Média Anual \\
\hline Nordeste & $(-)$ 8,0 & $(+) 4,61$ \\
\hline Sudeste & $(-) 10,0$ & $(+) 4,72$ \\
\hline Sul & $(-) 12,0$ & $(+) 7,2$ \\
\hline Centro-Oeste & $(-) 10,6$ & $(+) 11,36$ \\
\hline Brasil & $(-) 13,1$ & $(+) 9,40$ \\
\hline
\end{tabular}

Fontes: Dados Primários, FGV - Dados para o período 1994 a 1997, elaborados in Delgado, G. C. e Flores, JF. (1998), op.cit. p. 23; e para o período 2000/2006 cf. Gasques, J.G (2008), op.cit. pags. 6 e 8.

comparativamente à fase áurea de sua expansão -1979/81, (cf.Anuário Estatístico do Crédito Rural - 2009 e 2010 - Banco Central). Mas a partir dos anos 2000 a política monetária põe em curso um processo contínuo de recuperação do crédito rural bancário, a ponto de crescer em uma década (2000 a 2010) - 162\% em valor real, equivalente a uma taxa pouco acima dos 10\%.a.a.

Essa recuperação é planejada e de certa forma reproduz esquemas parecidos de engenharia financeira, daqueles adotados pela política monetária dos anos $70\left(^{6}\right)$ do século passado, abandonados por longo período, para somente agora retornarem, com devidas atualizações institucionais. O mecanismo adotado dessa engenharia fiscal e financeira consiste em direcionar parcelas importantes de recursos monetários (depósitos à vista do público, que não são remunerados) e fiscais (Fundos Constitucionais, FINAME-BNDES, FUNCAFÉ e outros recursos públicos) para aplicação compulsório no setor rural, ao mesmo tempo em que estimula por isenção fiscal a Caderneta de Poupança Rural como fonte secundária mais importante a prover recursos privados para o Sistema Nacional de Credito Rural. Essa sistemática se completa com a provisão importante de subvenções fiscais à taxa de juros do setor rural, sob o formato de equalizações (diferença da Taxa SELIC relativamente às taxas subvencionadas do SNCR), pagas pelo Tesouro aos Bancos (ver dados à Tabela 2) ( ${ }^{7}$ )

Mas o que chama em especial a atenção nesse arranjo de economia política é o formato de extração do excedente econômico, que o sistema engendra para fazer funcionar esse peculiar projeto, de que nos ocuparemos mais especificamente no item 4. 
A liquidez bancária em expansão é também fator coadjuvante à recuperação do preço da terra, que experimentará forte incremento em toda a década. Os ativos fundiários (terras), que na década dos anos 90 também haviam experimentado forte declínio, recuperam na década 2000 o processo de valorização, coetâneo ao 'boom' das 'commodities' mostrado na Tabela 3.

Por último, as principais cadeias agro industriais, daquilo que hoje se denomina oficialmente de 'agronegócio', assumem protagonismo nas exportações, puxadas por meia dúzia de produtos agropecuários - soja e milho, carnes, produtos florestais, cana de açúcar, café, couros e tabaco.

\section{Extração do Excedente Econômico pelo Setor Primário}

No seu livro de síntese teórica - "Introdução ao Desenvolvimento - Uma Abordagem Estrutural', Celso Furtado (2000) trata em linguagem didática nos capítulos'Apropriação do Excedente Econômico (cap. 6) e 'Estrutura Agrária na Formação do Excedente' (cap. 8) dos processos de produção e repartição do excedente econômico, dando particular destaque às economias primário-exportadoras. Farei uso desse acervo conceitual ao longo da análise desse tópico, adaptando-o às condições históricas concretas sob exame.

Observe-se que no item 2 deste artigo, evidenciamos um movimento de expansão da demanda por 'commodities' no comércio mundial, expresso sob a forma de quantidades e preços em forte ascensão, às quais as exportações brasileiras se incorporam ostensivamente depois da grave crise cambial de 1999. Somente a partir de então se articulam condições políticas internas e externas para forjar um virtual pacto de economia política - a parceria estratégica dos complexos agro industriais, da grande propriedade territorial e do Estado, tendo em vista uma peculiar inserção da economia brasileira nas novas demandas da economia mundial.

Os movimentos descritos nas seções 2 e 3 configuram condições 'mercantis' e de estado -ou 'autoritárias' na designação referida de Celso Furtado(2000), que irão forjar a produção e repartição de uma parcela relevante do excedente econômico brasileiro nas novas relações externas e internas que o País persegue depois da grave crise cambial de 1999.

Recorde-se que no primeiro movimento descrito, o Brasil se reinseriu no comércio mundial, depois de um período de certa estagnação (anos 90), mas o fez sob condições de certa especialização primário exportadora, capturando fatias relevantes de alguns mercados agropecuários e minerais em forte expansão.

No segundo movimento, o Estado reestrutura suas políticas de crédito, de comercialização e de terras, tendo em vista fomentar a acumulação de capital no espaço ampliado das cadeias agro industriais, mercado de terras e do sistema de crédito. Isto posto, configuram-se condições específicas para um determinado estilo de apropriação do excedente econômico. 
A expansão das exportações de "commodities" agro-minerais, que é impelida pela pressão para remuneração do capital estrangeiro (o déficit dos "serviços") e pela perda de competitividade da maioria dos setores industriais ${ }^{8}$, ressalta a presença de estruturas de acumulação de capital e captura do excedente econômico, fortemente ancoradas na teoria das vantagens comparativas naturais e da produtividade dos recursos da terra e das jazidas. Estas são abordagens teóricas clássicas do comércio internacional e da renda fundiária, ambas construídas nos primórdios do capitalismo, com a publicação em 1817 dos "Princípios de Economia Política e Tributação", de David Ricardo

A produtividade dos recursos naturais, ou o conceito antigo da teoria do comércio internacional - as vantagens comparativas dos recursos naturais - terras, e jazidas minerais, recursos hídricos etc., parece haver se convertido na grande aposta da inserção brasileira na divisão internacional do trabalho, com todos os riscos inerentes à assimetria dessa inserção; principalmente da instabilidade congênita de sua vinculação à remuneração do capital estrangeiro operante ou transitando na economia.

Mas o que chama a atenção nesse arranjo de economia política é o formato de extração do excedente econômico, que o sistema engendra para fazer funcionar esse peculiar projeto.

Sendo como é a produtividade dos recursos naturais o fator explicativo à inserção externa, cresce a importância da renda fundiária como componente essencial do excedente econômico que esse estilo de acumulação de capital perseguirá. Isto não exclui evidentemente a intensificação do pacote técnico por unidade de área, portanto, alguma inovação técnico-produtiva estará sendo incorporada à renda fundiária pelo capital. Mas a maior parte da inovação técnica terra-intensiva vinculase a um pacote tecnológico já disseminado há décadas na economia mundial, sob controle dos ganhos se produtividade de um número muito reduzido de empresas transnacionais do agronegócio.

A repartição do excedente econômico, no plano interno, na fase expansiva da demanda externa por "commodities", se caracteriza basicamente como modelo de "rendas de monopólio". Estas refletem, primeiramente a propriedade da terra e a forma ultra concentrada de sua distribuição; em segundo lugar, sua localização e a qualidade intrínseca dos recursos naturais explorados; em terceiro lugar, o acesso a fundos públicos subvencionados, propiciados pelas vantagens conferidas à emissão da dívida agrícola, sob respaldo de hipotecas; e finalmente, as patentes tecnológicas envolvidas na difusão do pacote técnico.

Em tais condições, para viabilizar, no plano externo, o volume e o ritmo de crescimento dos saldos comerciais primários, necessárias à solvência externa da Conta Corrente, haverá uma pressão endógena desse sistema por super exploração dos recursos naturais. A isto também se soma a pressão por concentração da propriedade fundiária, que é também forma peculiar de captura da renda da terra. Esses são os elementos cruciais que caracterizam a apropriação da renda fundiária, 
com conseqüências agrárias e ambientais altamente negativas do ponto de vista da equidade social.

Há uma dupla pressão por obtenção de ganhos de produtividade com recursos naturais. De um lado a incorporação de novas áreas ao espaço econômico explorado, atual e potencialmente. Nestes novos territórios, a expansão agrícola se inicia adotando pacote tecnológico pré-existente, e exercendo um consumo crescente de recursos naturais como solos, água, biodiversidade, florestas nativas, luminosidade, condições climáticas. De outro lado, nas zonas de agricultura já consolidada, haverá certamente pressão crescente por aumento de produtividade do trabalho mediante intensificação do pacote tecnológico agro-químico, com conseqüências ambientais também predatórias sobre o meio ambiente.

Por sua vez, à dinâmica de crescimento da produtividade física da agropecuária nas zonas consolidadas ou nas zonas de incorporação fundiária, não há evidência de correspondência com aumentos de salário, nem tampouco de elevação do emprego de trabalhadores não qualificados, vinculados ao crescimento da produção. Expansão agrícola e expansão do emprego e da massa salarial são fenômenos de outro contextos históricos - a expansão cafeeira em diversos ciclos de economia primário exportadora até final dos anos 60 do século passado. Em outros termos, a taxa de salário, o emprego e a massa salarial geradas no processo de produção e exportação de bens primários $^{9}$ não crescem ou até decrescem, enquanto que a produção e a exportação das principais cadeias agroindustriais se expandem a elevadas taxas de 8 a $10 \%$.a.a. Alguma dinâmica local de criação de novos empregos nas cadeias produtivas em expansão ocorrerá, mas nem de longe se compara com os fenômenos de expansão primária de outras épocas.

Conquanto o trabalho humano venha sendo crescentemente mitigado nos processos produtivos tipicamente capitalistas ou de agronegócio, as relações de trabalho que se estabelecem na produção agropecuária parecem configurar um estilo de "super-exploração", seja pela imposição de jornadas excessivas (corte de cana, por exemplo), seja pelo manejo de materiais agrotóxicos altamente nocivos à saúde humana, seja pelas relações de precária contratação de trabalhadores migrantes nos picos da demanda sazonal das safras agropecuárias.

A super exploração do trabalho aqui referida ${ }^{10}$, assim como a super exploração dos recursos naturais, se amalgamam na abordagem histórico-concreta do agronegócio brasileiro dos anos 2000. Neste sentido, é conceito útil e necessário para caracterizar o padrão de extração do excedente econômico que se realiza no quadro de relações internacionais fortemente assimétricas.

Por outro lado, deve-se distinguir outro processo em curso de extração da renda fundiária, que pouco tem a ver com a pura captura das vantagens comparativas naturais no formato clássico da teoria de David Ricardo. Exemplo mais notório desta segunda vertente de exploração de recursos naturais é a do progresso técnico precedendo e dirigindo a acumulação de capital. Também captura e persegue renda 
fundiária, a exemplo do caso da exploração do petróleo na Zona do Pré-Sal. Mas o processo produtivo se desencadeia pelo progresso técnico (inovações para exploração em águas profundas), com necessária intensificação de investimentos nas cadeias industriais de ponta (Química, Mecânica, Metalúrgica, Eletro-eletrônica etc), para ao final atender a demanda primária em expansão. Segue-se aqui uma seqüência causal do progresso técnico para a acumulação de capital, com criação de extensa rede inter industrial de demandas e inovações, para ao final do processo extrair o recurso natural, a ser posteriormente manufaturado em novas cadeias industriais. Esse processo difere teòricamente da expansão primária em reposta direta à demanda externa (caso do agronegócio), mas ambos estão impelidos por uma renda fundiária dos recurso naturais em expansão cíclica.

Há duas ordens de críticas que se pode fazer a esse estilo de expansão com base na exploração ou super exploração de recursos naturais. No caso típico do Pré-Sal, não se pode falar em atraso técnico, mas sim de custos sociais e ambientais invisíveis que podem comprometer sèriamente esse processo expansivo. Por outro lado, no caso típico da expansão agropecuária de 'commodities', a essa crítica dos custos sociais e ambientais, precisa-se considerar ainda sua relativa desvinculação das inovações de ponta do progresso técnico e industrial, susceptíveis de criar ondas secundárias e terciárias de novos produtos e novos mercados.

\section{Conclusões}

Do exposto nas seções precedentes, depreende-se que a inserção primária no comércio exterior; as relações de dependência subjacentes a tal inserção, expressas na Conta Corrente do Balanço de Pagamento; a exacerbada valorização da renda fundiária neste processo e as pressões coetâneas por super exploração de recursos naturais e do trabalho humano são fatos históricos que se integram num todo articulado. Constituem a configuração de uma estratégia estatal-privada de acumulação de capital, que de certa forma conforma o próprio padrão de crescimento econômico perseguido nesta década pelo agronegócio. Esse padrão se expande para o conjunto da economia, conferindo certo rumo ao crescimento mais geral da economia brasileira nesta primeira década do século XXI.

Se atentarmos para a estrutura econômica dos setores que já crescem à frente dos demais, há alguns anos, veremos que existe certo denominador comum presente na produção do petróleo, da hidroeletricidade, do agronegócio e também da mineração. Todos esses ramos produtivos operam com base em monopólio de recursos naturais, que nas suas dotações originais independem de investimentos ou da aplicação do trabalho humano para produzi-las Esses recursos, submetidos à exploração intensiva ou extensiva, derivada da demanda por 'commodities', produzem rendas fundiárias, que são objeto de ávida disputa no processo de apropriação da renda e da riqueza social. 
Dada a atual configuração da inserção do Brasil no comércio mundial, os recursos naturais passaram a figurar como vetor principal de competitividade externa. O pressuposto dessa competitividade, baseada em estoques finitos de recursos naturais, é preocupante por varias razões. As matérias-primas aí produzidas apresentam baixa agregação de trabalho humano; há forte pressão por super exploração dos recursos naturais em curto prazo; e a inovação técnica de ponta do sistema industrial fica relativamente relegada ao segundo plano, (exceto no caso do Petróleo - Pré-sal), porque os ganhos produtividade do subsistema exportador estão muito mais ligados às chamadas vantagens comparativas naturais.

Temos uma armadilha grave nesse quadro estratégico. Competitividade externa de "commodities" agrícolas e minerais, apoiada no argumento da produtividade da terra e das jazidas minerais disponíveis, sustenta um fluxo de transações correntes com o exterior dependente de capital estrangeiro. A resultante inevitável é super exploração de jazidas e terras novas e também intensificação do pacote técnico agroquímico nas zonas já exploradas, para obter maior fatia do mercado externo de produtos primários. Esse arranjo não é sustentável, em médio prazo, econômica e ecologicamente. Os tais ganhos de produtividade das exportações de minerais, petróleo, carnes, grãos, etanol etc., deixados a critério estritamente mercantil, tendem a se extinguir no tempo com a dilapidação paulatina dos recursos naturais não renováveis.

Por outro lado, o perfil distributivo deste modelo não é menos perverso. Os ganhos de produtividade na fase expansiva das "commodities" viram renda da terra e do capital, capturadas privadamente pelos proprietários das terras, das jazidas e do capital; mas os custos sociais e ambientais da super exploração desses recursos e do trabalho precarizado aí envolvido são da sociedade como um todo. Compensações se tornam necessárias, mas não seriam remédio suficiente para suprir os custos sociais degradantes do trabalho e do meio ambiente.

Este quadro econômico de produção e repartição do excedente econômico não se compraz com democracia política e social. Não está claro que o governo atual tenha clareza de sua não sustentabilidade em médio prazo. O sistema tributário e a política social provavelmente teriam que extrair e redistribuir uma parcela muito grande da renda da terra e do capital para suprir necessidades básicas; e ainda que o fizesse não resolveria o problema de fundo. Mas como fazê-lo se esse sistema estiver sob controle político dos donos da riqueza fundiária?

Em síntese, as condições da expansão agrícola vinculadas a:

uma inserção externa dependente;

ao perfil da dupla super exploração dos recursos naturais e do trabalho humano e a uma forma de extração do excedente econômico, fortemente vinculada à renda fundiária;

configuram novos ingredientes de uma questão agrária muito além dos limites setoriais da agricultura. Em última instância, caracterizam um estilo típico 
do subdesenvolvimento, que se repõe em pleno século XXI e do qual o pacto do agronegócio é parte integrante de peso. Mas a caracterização dessa questão agrária é mais geral e mais profunda. Integra a essência do projeto nacional de subdesenvolvimento ${ }^{11}$ e requer um enfrentamento dentro e fora do modelo agrícola hegemônico. Evidentemente essa abordagem suscitaria um debate em perspectiva, com vistas à superação desses constrangimentos ao desenvolvimento, tema que escapa aos limites específicos deste artigo.

Finalmente, deve-se atentar para o fato de que a eventual emergência de crises financeiras globais que venham interromper o ciclo atual da demanda externa por 'commodities', provavelmente retrairiam a liquidez do mercado internacional de capitais, provocando dupla pressão sobre a dependência externa de países exportadores primários. Com isto, o padrão de crescimento assentado nesses setores se veria comprometido Essa hipótese de crise do modelo atual, abre oportunidade para o País mudar o seu atual perfil de inserção externa. Em síntese, o futuro é aberto, mas ficará muito parecido ao passado se repetir os ciclos de mudança econômica dos últimos 50 anos.

\section{Notas}

A 'Balança de Pagamentos' tècnicamente acumula os saldos (positivos ou negativos) da Conta Corrente e do Investimento Estrangeiro. Em caso de soma negativa desses fluxos em determinado ano, necessàriamente caem as Reservas em moeda estrangeira do país em questão.

2 A formação de uma estratégia de capital financeiro na agricultura brasileira estrutura-se com a modernização técnica dos anos de 1970. Essa modernização dissemina relações inter industriais com a agricultura, mediadas pelo crédito rural subsidiado; este, por sua vez aprofunda também no período a valorização da propriedade fundiária, com ou sem modernização técnica (ver Delgado, G.C.1985).

3 O Plano Plurianual de governo (2000)/2003), do II Governo FHC, elege os eixos territoriais de desenvolvimento como programa prioritário, naquilo que denominou "Brasil em Ação",e que consiste num conjunto de compromissos de investimento em obras rodoviárias, ferroviárias e portuárias, tendo em visita a melhoria e ampliação da infra-estrutura territorial no Sudeste, Centro-Oeste, Norte e Nordeste. Os investimentos efetivamente realizados foram de pouca monta, mas boa parte desses projetos será retomada no Programa de Aceleração de Crescimento - PAC, do II Gov. Lula, 2006-2010.

4 As exportações físicas de carne bovina, carne de frango, soja, milho e açúcar crescerão aceleradamente no período 2000/2008, respectivamente às taxas médias anuais de 15,0 12,0,9,8 e 10,6\% para os quatro primeiros produtos e acima de 15\% para o binômio açúcar /álcool (cf Delgado, Guilherme(2008) op.cit).

5 Para uma análise das transações externas da economia brasileira no período, ver Delgado, Guilherme (2009) "O Setor Primário e o Desequilíbrio Externo" - op. cit.

6 Para uma análise da política monetária vinculada à expansão do crédito rural no período 1965-84, ver Delgado, Guilherme (1985) ,pags. 66-75 - op. cit.

7 Para uma análise mais abrangente do relançamento do crédito rural bancário no período sob análise ver Delgado, Guilherme C.(2012) - cap. 5 - op. cit.

8 Segundo trabalho recente de autoria dos professores Luiz Gonzaga Belluzzo e Julio Gomes de Almeida (Carta Capital de 22/06/2011 - p. 40/41) intitulado o "Mergulho da Indústria", a indústria de transformação involuiu significativamente no comércio externo entre 2004 e 2010, de um superávit inicial de 24,0 bilhões de dólares para um déficit de 34,8 bilhões em 2010.

9 Segundo a informação dos Censos Agropecuários de 1996 e 2006 o "Pessoal Ocupado" na agropecuária decresceu na década inter censitária (-7,2\%) passando de 17,85 para milhões de pessoas em 1996 para 16,57 milhões em 2006. 
10 A super exploração do trabalho na abordagem marxista da "Dialética da Dependência", de Rui Mauro Marini (op.cit) é criticada por Fernando H. Cardoso em estudo do CEBRAP de 1978. A polêmica é sobre, se essa é característica essencial ou acidental do desenvolvimento capitalista na periferia, segundo enfoque o enfoque marxista que Cardoso e Marini então disputavam.

11 Para uma exposição didática da teoria do subdesenvolvimento ver Celso Furtado (2000) - "Introdução ao Desenvolvimento - Enfoque Histórico Estrutural" - Rio de Janeiro - Ed. Paz e Terra - $3^{\circ}$ edição especialmente os capítulos VI, VII e VIII, que tratam da apropriação do excedente econômico.

\section{Referências Bibliográficass}

BANCO CENTRAL, Anuário Estatístico do Crédito Rural, 2009 e 2010.

BELUZZO, L. G. e ALMEIDA, Julio G. - “O Mergulho da Indústria” in Carta Capital 22/06/2011

DELGADO, Guilherme C. (1985) - Capital Financeiro e Agricultura no Brasil, 1965-1985 - São Paulo - INCONE/UNICAMP - 1985

DELGADO, G. C. e FLORES, J. F. (1998) - “Determinantes da Queda Recente do Preço da Terra no Brasil" in Economia Ensaios, Vols 12/13, n 1 e 2, julho/dez. de 1998 (Departamento de Economia da UFU).

DELGADO, G. C (2008) - "Tensões Externas e Internas sobre os Preços dos Alimentos” in CONAB Abastecimento e Segurança Alimentar - O Crescimento da Agricultura e a Produção de Alimentos no Brasil - Brasília - CONAB, 2008.

DELGADO, G. C. (2009) - "O Setor Primário e o Desequilíbrio Externo" in CONAB - Agricultura e Abastecimento Alimentar - Políticas Públicas e Mercados Agrícolas - Brasília - CONAB - 2009.

DELGADO, Guilherme C., 2012.'Do Capital Financeiro na Agricultura à Economia do Agronegócio - Meio Século de Mudanças Cíclicas (1965-2012)' -(no prelo)

FURTADO, Celso (2000) - Introdução ao Desenvolvimento - Enfoque Histórico Estrutural - Rio de Janeiro - PAZ E TERRA, 2000.

GASQUES, José G. (2008) - "Preços da Terra no Brasil” in Anais do XLVI Congresso da Sociedade Brasileira de Economia Rural -SOBER, Rio Branco, Acre, 2008

IBGE, 1996. Censo Agropecuário de 1995-1996. Disponível em: < http://www.ibge.gov.br/home/ estatistica/economia/agropecuaria/censoagro/1995_1996/default.shtm>.

2006. Censo Agropecuário 2006. Disponível em: < http://www.ibge.gov.br/home/estatistica/economia/agropecuaria/censoagro/default.shtm $>$.

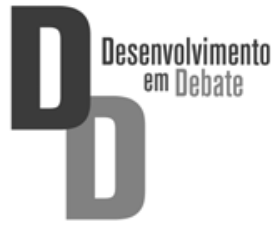


